\title{
The Archaeology of Alchemy and Chemistry in the Early Modern World: An Afterthought
}

\author{
Marcos Martinón-Torres*
}

Bolstered by famous novels such as Paulo Coelho's The Alchemist or J. K. Rowling's Harry Potter and the Philosopher's Stone, or more academic works such as Mircea Eliade's The Forge and the Crucible, the popular perception of early alchemy tends to associate it to philosophy, psychology and magic much more than to modern science. Ideas such as the philosopher's stone, or the transmutation of base metals into gold, are often linked to allegories of the personal transformation or irrational upsurges of an adept who pursues a dream in spite of the difficulties, or one who possesses extraordinary powers and arcane knowledge. Magic, occult arts, religion and mysticism seem to take a much more prominent role than crucibles, alembics or furnaces. These caricatures may apply to some 21st-century alchemists, but they are far from representing medieval and early modern alchemists. Perhaps even more worrying is the fact that these anachronistic misconceptions are also ingrained in academic literature. Teachers of the history of science often present the development of their discipline as a process that took place 'in spite of alchemy' or, at least, once the Scientific Revolution shed light on alchemical obscurity and superstition.

Part of the problem behind this historiographic bias lies in the lack of contextual sensitivity of some of the pioneer

\footnotetext{
UCL Institute of Archaeology,

19th- and 20th-century historians of science. When confronted with the often incomprehensible writings by medieval and early modern alchemists, supplemented by the period paintings, woodcuts and allegorical emblems, they found a world that, upon first sight, seemed very different from their own. The many references to actual materials and experiments present in alchemical treatises were largely overlooked or sidelined, partly because they appeared muddled in confusing language or because, transposing present ideas to the past, historians assumed that alchemy had more to do with the supernatural than with the natural. The overemphasis on documented examples of historical charlatans and fraudsters has not helped the alchemists' reputation either. Thus Renaissance 'alchemy' and 'chemistry' have often been artificially segregated, and some scholarly work has perpetuated the popular image of the alchemical laboratory as an unruly space for darkness, superstition or greed. Little work has been carried out to investigate the relationships between the adepts seeking metal transmutation, those exploiting natural wealth for other purposes, and those systematically investigating the secrets of nature for the sake of knowledge. The focus on theories and stereotypes has downplayed the practical side of alchemy and, with it, its relevance to the history of science.

But things are beginning to change. Recent studies have started to use laboratory notebooks and a more rigorous and scienceinformed textual analysis to reconstruct the 


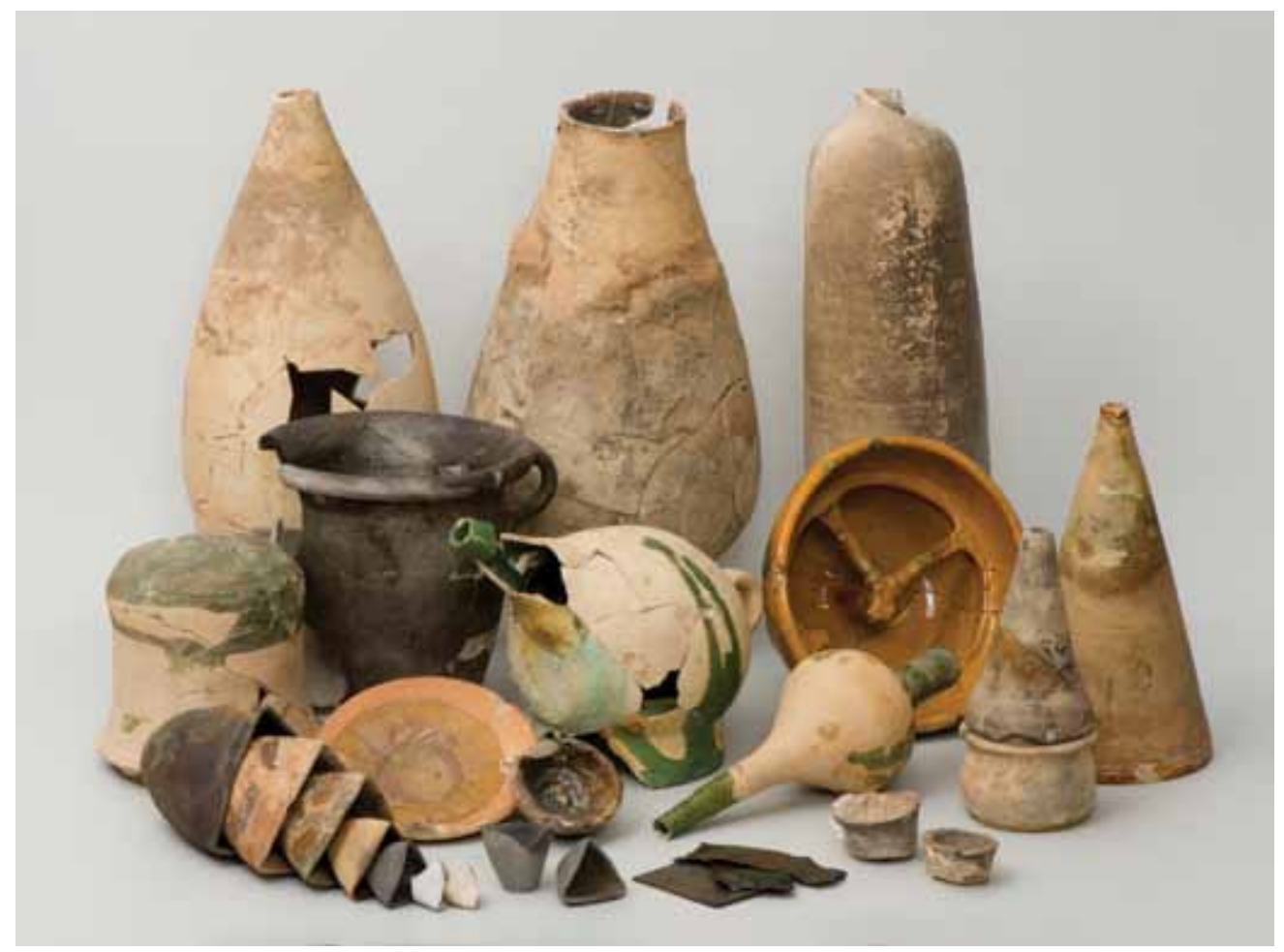

Fig. 1: Some of the 1,000 instruments recovered in the 16th-century laboratory of Oberstockstall, Austria (photo Andreas Rausch).

practical dimensions of early alchemy. These approaches, together with ongoing archaeological work, are increasingly emphasising that theoretical formulations were based on actual laboratory experiments, that chrysopoeia or goldmaking was but one within a wider repertoire of practical endeavours, and that alchemy cannot be studied in isolation from metallurgy and medicine. Alchemy and chemistry have only existed as self-identified different fields since the 18th century.

During 2011 I enjoyed research leave funded by a Fellowship from the Arts and Humanities Research Council, to complete major strands of research, write-up and public engagement for my project 'The Archaeology of Alchemy and Chemistry in the Early Modern World'. This project builds on previous work I have been carrying out for the last few years in collaboration with a good number of colleagues and students, seeking to squeeze out the informative potential existing in the growing number of archaeological laboratories recovered around the world. These laboratories include a wide range of contexts and activities. Among others, we have studied the exceptionally well-equipped laboratory from the chapel of Oberstockstall (Austria) (Fig. 1), a small and secluded laboratory found in an underground gallery in Kapfenberg (Austria), and the laboratory remains found in Quebec and Jamestown (Fig. 2) - respectively, the first French and English attempts at permanent settlements in America. To these we can add another highlight: the Old Ashmolean laboratory in Oxford, founded in the late 17 th century as the first university laboratory in Britain, and initially directed by Robert Plot. Much of my time during 2011 was spent revisiting these sites and the archaeologists who excavated and curated the assemblages - too many to name here, but without whom this work would be impossible. I collected samples, conducted analyses, read and wrote 
- but I also found time to give a number of talks to a range of audiences in several countries, as well as to make some contributions to mass media.

The scientific analysis of archaeological laboratories provides a useful approach to redress the anachronism, undue generalisation and theoretical biases of some historical work. By analysing the origins and quality of the laboratory instruments in their context, as well as the residues that inform about the experiments carried out with them, it is possible to access the practical dimension of the laboratory, the technical knowledge of individual practitioners and their underlying understanding of nature. It is not by coincidence that the alchemical laboratory is the first place ever designed specifically to facilitate the combination of theory and practice, well before the official birth of the scientific method'. As a matter of fact, the awareness of natural laws and of the properties of materials that we can infer from archaeological data reveals that many scientific achievements were made in alchemical laboratories, and much earlier than apparent from historical sources. Furthermore, the material remains illustrate a great array of experiments and discoveries in addition to goldmaking, such as processes with zinc, mercury and glass, which will hopefully encourage historians of science and technology to diversify their research foci.

From a broader archaeological perspective, laboratories constitute a relatively new research area with recognisable relevance to historical and colonial archaeology. For example, the laboratories in Quebec and Jamestown mentioned above illustrate how important it must have been for early settlers to bring specialists with the ability to study natural materials. My ongoing analyses sometimes reveal the very disappointing results of the first trials with new minerals carried out in America, going some way to explain the frustration and eventual failure of the earliest colonial enterprises. At the same time, for those interested in materials

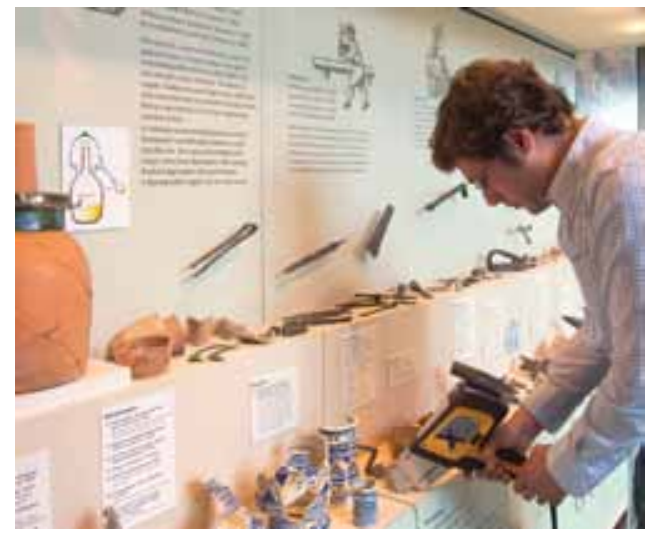

Fig. 2: Using a portable XRF to analyse archaeological artefacts at the Archaearium in Jamestown, Virginia (photo Michael Lavin).

analysis, archaeological laboratories often pose interesting challenges requiring a consideration of metallurgy, ceramics, glass and even other materials and specialities, since we cannot predict a priori the types of experiments undertaken by individual alchemists, and often they will overlap several material categories.

Above and beyond disciplinary boundaries, there is an idea emerging from this recent wave of archaeological and historical scholarship that is relevant to a wide spectrum of current researchers, policy makers and the public alike. This is the importance of big hypotheses and serendipity. Much alchemical research was carried out in the pursuit of metal transmutation - a bold but epistemologically sound hypothesis that was eventually falsified. This conclusion was reached only after centuries of much experimentation and theorisation, and of course it raised a great deal of scholarly disputes. However, notwithstanding the privileged position offered by our historical perspective - we now know that their hypothesis was false - we should not underestimate the significance of the alchemical quest. Contrary to common belief, many early modern alchemists worked on the crest of the wave of empirical knowledge and constantly chal- 
lenged established knowledge; at the same time, they tirelessly tested bold hypotheses and conducted experiments for the sake of explaining their world; in so doing, they made exceptional serendipitous discoveries. It was through their constantly evolving experiment-based theories that the very paradigm that had inspired their work was eventually rejected, paving the way for the separation between what would be called chemistry and what would derive into the present-day alchemical gibberish.

Reflecting upon this evidence, research funding bodies and higher education institutions should take notice that research programmes overly focused on immediate results, tightly constrained feasibility and coherence with previous scholarship are not necessarily the most insightful. Modern chemistry is the combined result of human ambition, ingenuity, big hypotheses and serendipity. It is only because alchemists creatively developed the necessary equipment, experimental methods, and intellectual sagacity to pursue their ambitious quest that we understand our world the way we do. The real challenge, therefore, is to combine the tools of science with the ability to go off the rails. There is much to say for frontier research that actively questions established 'truths' or allows for serendipity by simply exploring for the sake of it.

Archaeologists and historians are sometimes frustrated because they cannot predict the results of an excavation or archive search. Our drive to come up with research questions and hypotheses that can be tested against the data should certainly continue but this is not as the only way. Not knowing what lies beneath - quite literally in the case of archaeologists - adds to the joy of discovery, but it also heightens our senses to appreciate the significance of the unexpected. A list of the top ten archaeological discoveries of all time would surely include some welldefined question-based projects, but also serendipitous finds whose significance was subsequently valued and developed by wellresourced professionals. So why privilege the first approach only? Alchemists did not find the philosopher's stone but they did find modern chemistry instead. In so doing, they established much of the basis of how many of us relate to one another and the surrounding world today. Whether this was a good or a bad outcome may be a matter for debate but the fact cannot be ignored. 